\title{
Psychosocial Attributes of Maternal Thoughts of Self-harm during Puerperium
}

Hrishikesh B Nachane

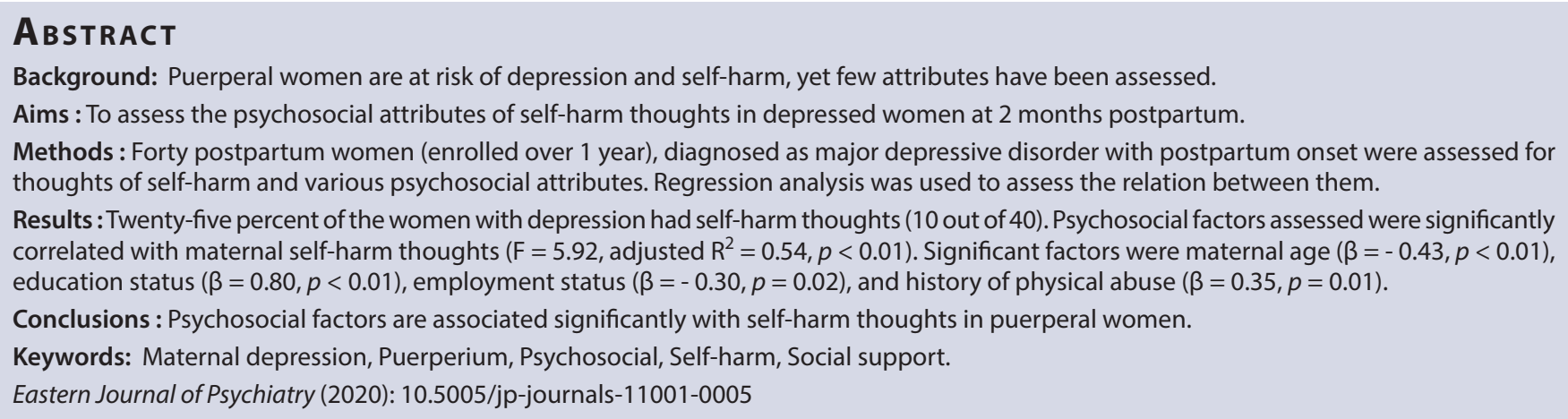

\section{INTRODUCTION}

Puerperium is a hectic period for all mothers as they are recovering from child birth and adjusting to their new role. ${ }^{1}$ It is usually associated with sleep, appetite disturbances, fatigue, and stress for caring for a new born. However, mothers are also particularly susceptible to develop psychopathology and suicidal thoughts during this period. ${ }^{2}$ Thoughts of self-harm are present in as much as $16.97 \%$ of the population and up to $6.16 \%$ report suicidal ideation, which can extend up to a year postpartum. ${ }^{3}$ Although most women with suicidal ideations are at low risk for committing suicide, their timely assessment is essential in preventing completion of suicide. ${ }^{4}$ Hence it is imperative to study factors related to self-harm in this population. However, few Indian studies have looked in to this and hence the present study was formulated.

There is significant evidence that social support plays a significant role in majority of psychopathological disorders. ${ }^{5}$ In relation to maternal depression, it has been seen that chronic stressors especially financial and housing problems, negative life events, and inadequate social support were all linked to high depressive symptomatology during pregnancy. ${ }^{6}$ This is more pronounced in mothers with a lower socioeconomic status. ${ }^{6}$ It has also been that apart from the quality of perceived social support, relations with mother and partner have been associated with antenatal depression. ${ }^{7}$ With respect to suicide it has been highlighted that recent life events, such as divorce, unemployment, and death/illness in the family in the last 3 months were important in men and women who committed suicide. ${ }^{8}$ Howard et al. have shown that women were more likely to experience suicidal ideation at baseline if they were younger, unmarried, unemployed, or had a partner that was unemployed. ${ }^{9}$ Few factors that have been neglected are physical abuse, substance dependence in husband, and sexual incompatibility. The present study assessed psychosocial attributes of women suffering from maternal depression with self-harm thoughts.
Department of Psychiatry, TNMC \& BYL Nair Ch Hospital, Mumbai, Maharashtra, India

Corresponding Author: Hrishikesh B Nachane, Department of Psychiatry, TNMC \& BYL Nair Ch Hospital, Mumbai, Maharashtra, India Phone: +91 7767096416, e-mail: hbnachane@gmail.com

How to cite this article: Nachane HB. Psychosocial Attributes of Maternal Thoughts of Self-harm During Puerperium. East J Psychiatry 2020;23(1):27-29.

Source of support: Nil

Conflict of interest: None

\section{Methodology}

The present analysis was undertaken in the Department of Psychiatry of a tertiary care center in western India. Ethical clearance was obtained from the Institutional Ethics Committee (Protocol no: EC/192/2015). We enrolled all the mothers referred to our department for assessment; who were in their first two months of puerperium and who satisfied the DSM 5 criteria for major depressive disorder with peripartum onset during the period of June 2016 to May 2017 (1 year). Women having past and present history of medical illness, psychiatric illness or on any medications were excluded. The final sample size turned out to be 40 . Patients were explained about the nature of the study and written informed consent was obtained from them. A semistructured pro forma was devised to assess if they had any thoughts of self-harm (answered yes or no) and also to enquire into determinants of their social environment during the postpartum period and patients were asked to comment about them. The social factors considered were maternal age, type of family, education status, employment status of the mother, relationship with husband, history of substance abuse in husband, history of physical abuse in the mother, sexual incompatibility and sexual fears, husband's income, and perceived social support during the pregnancy and postpartum. SPSS 20.0 was applied for statistical analysis. Data are expressed as mean plus

\footnotetext{
(c) The Author(s). 2020 Open Access This article is distributed under the terms of the Creative Commons Attribution 4.0 International License (https://creativecommons. org/licenses/by-nc/4.0/), which permits unrestricted use, distribution, and non-commercial reproduction in any medium, provided you give appropriate credit to the original author(s) and the source, provide a link to the Creative Commons license, and indicate if changes were made. The Creative Commons Public Domain Dedication waiver (http://creativecommons.org/publicdomain/zero/1.0/) applies to the data made available in this article, unless otherwise stated.
} 
or minus standard deviation for continuous variables and as percentage for categorical variables. Regression analysis was used to establish association of social variables with thoughts of selfharm self-harm using the backward elimination method, in which all factors were entered initially and factors were consecutively eliminated until a significant model was achieved ( $p$ value $<0.05$ ). Effect size was determined by standardized coefficients $(\beta)$.

\section{Results}

Over a period of 1 year, 40 mothers were assessed in our department who fulfilled the criteria of major depressive disorder with peripartum onset by DSM 5, and these 40 mothers were further taken for analysis. Out of 40 subjects, 10 had thoughts of self-harm (25\%). Table 1 represents the distribution of their social variables among depressed mothers with and without self-harm thoughts. No subject had a history of self-harm attempt or suicide. Regression analysis was then undertaken to see which psychosocial attributes were significantly associated with self-harm thoughts in maternal depression. The factors which were included in the model were type of family, maternal age, relationship with husband, education status, occupation, history of substance abuse in husband, history of physical abuse in the mother, perceived social support, and husband's income. History of sexual incompatibility did not contribute to the model. The overall model had an adjusted $\mathrm{R}^{2}$ of 0.54 and $p<0.01$. Significant factors in the present model were maternal age $(\beta=-0.43, p<0.01)$, education status $(\beta=0.80$, $p<0.01)$, employment status $(\beta=-0.30, p=0.02)$, and history of

Table 1: Table showing distribution of psychosocial attributes in the two groups

\begin{tabular}{|c|c|c|}
\hline Psychosocial attributes & $\begin{array}{l}\text { Distribution in } \\
\text { group with self- } \\
\text { harm thoughts } \\
\quad(n=10)\end{array}$ & $\begin{array}{l}\text { Distribution in } \\
\text { group without self- } \\
\text { harm thoughts } \\
(n=30)\end{array}$ \\
\hline Type of family & $\begin{array}{l}\text { Nuclear }=2(20 \%) \\
\text { Joint }=8(80 \%)\end{array}$ & $\begin{array}{l}\text { Nuclear }=7(23 \%) \\
\text { Joint }=23(77 \%)\end{array}$ \\
\hline Maternal age (years) & $25.1 \pm 3.28$ & $26.59 \pm 5.02$ \\
\hline Education status & $\begin{array}{l}\text { Uneducated = } 9 \\
(90 \%) \\
\text { Educated }=1 \\
(10 \%)\end{array}$ & $\begin{array}{l}\text { Uneducated = } 8 \\
(27 \%) \\
\text { Educated }=22 \\
(73 \%)\end{array}$ \\
\hline Occupation & $\begin{array}{l}\text { Unemployed = } 5 \\
(50 \%) \\
\text { Employed }=5 \\
(50 \%)\end{array}$ & $\begin{array}{l}\text { Unemployed = } 8 \\
(27 \%) \\
\text { Employed = } 22 \\
(73 \%)\end{array}$ \\
\hline Relationship with husband & $\begin{array}{l}\text { Cordial = } 9(90 \%) \\
\text { Strained = } 1 \\
(10 \%)\end{array}$ & $\begin{array}{l}\text { Cordial = } 26(87 \%) \\
\text { Strained }=4(13 \%)\end{array}$ \\
\hline $\begin{array}{l}\text { Substance abuse in } \\
\text { husband }\end{array}$ & $\begin{array}{l}\text { Present }=4(40 \%) \\
\text { Absent }=6(60 \%)\end{array}$ & $\begin{array}{l}\text { Present }=10(33 \%) \\
\text { Absent }=20(67 \%)\end{array}$ \\
\hline History of physical abuse & $\begin{array}{l}\text { Present }=1(10 \%) \\
\text { Absent }=9(90 \%)\end{array}$ & $\begin{array}{l}\text { Present }=1(3 \%) \\
\text { Absent }=29(97 \%)\end{array}$ \\
\hline Sexual incompatibility & $\begin{array}{l}\text { Present }=1(10 \%) \\
\text { Absent }=9(90 \%)\end{array}$ & $\begin{array}{l}\text { Present }=1(3 \%) \\
\text { Absent }=29(97 \%)\end{array}$ \\
\hline $\begin{array}{l}\text { Husband's income } \\
\text { (in rupees / month) }\end{array}$ & $\begin{array}{l}14,448.13 \pm \\
11,245.11\end{array}$ & $\begin{array}{l}14,739.44 \pm \\
9,301.28\end{array}$ \\
\hline Perceived social support & $\begin{array}{l}\text { Inadequate = } 2 \\
(20 \%) \\
\text { Adequate }=8 \\
(80 \%)\end{array}$ & $\begin{array}{l}\text { Inadequate = } 7 \\
(23 \%) \\
\text { Adequate = } 23 \\
(77 \%)\end{array}$ \\
\hline
\end{tabular}

physical abuse $(\beta=0.35, p=0.01)$. Looking at the effect sizes $(\beta)$, it was highest for education status (0.80), implying this was the most important risk factor in the present analysis, followed by maternal age $(-0.43)$ as mentioned in Table 2.

\section{Discussion}

Our analysis showed that $25 \%$ of mothers with maternal depression reported self-harm thoughts. Previous literature has shown selfharm thoughts to range from $8-10 \% .{ }^{9}$ One year prevalence studies have shown that $16.97 \%$ mothers reported thoughts of self-harm while $6.16 \%$ reported suicidal ideations. ${ }^{3}$ Suicidal thoughts have been shown to be higher in women with depression, especially from clinical samples, and this can explain the higher prevalence of self-harm thoughts in maternal depression as well. ${ }^{10}$ No women had a history of suicide attempt in the sample. It has been seen that most postnatal women with depression who have self-harm thoughts are not acutely suicidal and the rates of attempts are low. ${ }^{4}$ Biological changes during pregnancy have been postulated to account for the discrepancy between higher cognitions and fewer attempts. ${ }^{10}$

Social environment of the mother during pregnancy and puerperium is conducive towards her mental health and as such it is imperative to understand the factors that might play a role in self-harm. ${ }^{5}$ The present study found that psychosocial attributes such as type of family, maternal age, relationship with husband, education status, occupation, history of substance abuse in husband, history of physical abuse in the mother, perceived social support, and husband's income made significant contribution in the multivariate analysis. Maternal age has been seen as a significant factor in maternal depression, ${ }^{11}$ and it is not surprising that younger mothers have more thoughts of self-harm. Women who express self-harm thoughts have been found to be significantly younger, more likely to be single, and less educated. ${ }^{11}$ Our study has similarly highlighted that a younger maternal age and lower education status both are risk factors in self-harm thoughts. Unemployment and low income of the husband similarly proved to be risk factors for self-harm in mothers. Other studies have similarly shown that both partner's and patient's unemployment is a potential risk factor for self-harm thoughts. ${ }^{9}$ Added financial burden of a newborn, in an existing financially backward household can fuel stress, depression, and thoughts of self-harm. ${ }^{9}$

Data has shown that unmarried mothers and mothers with poor social support have higher chances of both psychopathology and self-harm. ${ }^{10}$ Our analysis similarly has shown that poor social support to be a contributing factor. Social support is one of the key protective factors against depression and self-harm. What is also important to note that relations with husband, use of substance in husband, and history of physical abuse were important factors. This stresses the role of husband and good conjugal relations as key factors in allaying self-harm thoughts during puerperium. Strained relations with husband, particularly during puerperium may increase stress in the mother contributing to self-harm thoughts, as has been previously reported. ${ }^{4}$ Overall adjusted $R^{2}$ was 0.54 , indicating $54 \%$ of self-harm thoughts can be attributed to psychosocial factors presently studied and yet there are other risk factors to be considered, which can drive future research endeavors. Interdependence among the factors measured could also explain the moderate strength of association in the present analysis.

Our study was not without limitations. The sample derived was small and only limited psychosocial factors were considered. More research with a prospective design using standard scales are 
Social Factors and Maternal Self-harm

Table 2: Regression analysis for self-harm thoughts and psychosocial attributes

\begin{tabular}{|c|c|c|c|c|c|}
\hline \multirow[b]{2}{*}{ Psychosocial attributes } & \multicolumn{2}{|c|}{ Unstandardized coefficients } & \multirow{2}{*}{$\begin{array}{c}\text { Standardized } \\
\text { coefficients } \\
(\beta)\end{array}$} & \multirow[b]{2}{*}{$t$} & \multirow[b]{2}{*}{$p$} \\
\hline & $B$ & Standard Error & & & \\
\hline Type of family & 0.18 & 0.11 & 0.25 & 1.67 & 0.11 \\
\hline Maternal age & -0.04 & 0.01 & -0.43 & -3.21 & $<0.01 *$ \\
\hline Relationship with husband & 0.06 & 0.22 & 0.04 & 0.27 & 0.79 \\
\hline Education status & 0.71 & 0.12 & 0.80 & 6.17 & $<0.01 *$ \\
\hline Occupation & -0.28 & 0.11 & -0.30 & -2.44 & $0.02 *$ \\
\hline History of substance abuse in husband & -0.18 & 0.13 & -0.19 & -1.36 & 0.18 \\
\hline History of physical abuse & 0.69 & 0.25 & 0.35 & 2.75 & $0.01 *$ \\
\hline Perceived social support & 0.22 & 0.15 & 0.21 & 1.32 & 0.19 \\
\hline Husband's income & 0.00 & 0.00 & 0.00 & 0.03 & 0.98 \\
\hline
\end{tabular}

Adjusted $\mathrm{R}^{2}=0.54, \mathrm{~F}=5.92{ }^{*} p<0.01$

*Statistically significant.

thus warranted. In conclusion, psychosocial environment does have a glaring impact on maternal thoughts of self-harm. Family is also the first to intervene in case of self-harms and the present analysis highlights their role in puerperium. Psychosocial factors of key importance as per the present analysis are maternal age, education status, occupation, and history of physical abuse, and role of many novel factors was highlighted. Effective screening strategies thus need to be outlined keeping them in mind. These can significantly help in reducing maternal suicide and mortality.

\section{References}

1. Kendell RE, Chalmers JC, Platz C. Epidemiology of puerperal psychoses. Br J Psychiatry 1987;150:662-673. DOI: 10.1192/ bjp.150.5.662

2. Mangla K, Hoffman MC, Trumpff $C$, et al. Maternal self-harm deaths: an unrecognized and preventable outcome. Am J Obstet Gynecol 2019;221:295-303. DOI: 10.1016/j.ajog.2019.02.056

3. Pope CJ, Xie B, Sharma V, et al. A prospective study of thoughts of self-harm and suicidal ideation during the postpartum period in women with mood disorders. Arch Womens Ment Health 2013;16:483-488. DOI: 10.1007/s00737-013-0370-y

4. Kim JJ, La Porte LM, Saleh MP, et al. Suicide risk among perinatal women who report thoughts of self-harm on depression screens. Obstet Gynecol 2015;125:885-893. DOI: 10.1097/ AOG.0000000000000718
5. Cairney J, Boyle M, Offord DR, et al. Stress, social support and depression in single and married mothers. Soc Psychiatry Psychiatr Epidemiol 2003;38:442-449. DOI: 10.1007/s00127-003-0661-0

6. Séguin L, Potvin L, Denis MS, et al. Chronic stressors, social support, and depression during pregnancy. Obstet Gynecol 1995; 85: 583-589. DOI: 10.1016/0029-7844(94)00449-N

7. SéAguin L, Potvin L, Denis MS, et al. Socio-environmental factors and postnatal depressive symptomatology: a longitudinal study. Women Health 1999;29:57-72. DOI: 10.1300/j013v29n01_05

8. Heikkinen M, Aro H, Lönnqvist J. Recent life events, social support and suicide. Acta Psychiatr Scand 1994;89:65-72. DOI: 10.1111/j.16000447.1994.tb05805.x

9. Howard LM, Flach C, Mehay A, et al. The prevalence of suicidal ideation identified by the Edinburgh Postnatal Depression Scale in postpartum women in primary care: findings from the RESPOND trial. BMC Pregnancy Childbirth 2011;11:57. DOI: 10.1186/1471-2393-11-57

10. Newport DJ, Levey LC, Pennell PB, et al. Suicidal ideation in pregnancy: assessment and clinical implications. Arch Womens Ment Health 2007;10:181-187. DOI: 10.1007/s00737-007-0192-x

11. Wisner KL, Sit DK, McShea MC, et al. Onset timing, thoughts of self-harm, and diagnoses in postpartum women with screen-positive depression findings. JAMA Psychiatry 2013;70:490-498. DOI: 10.1001/ jamapsychiatry.2013.87 